\title{
Amelioration of Inflammation and Cytotoxicity by Dipyridamole in Brain Endothelial Cells
}

\author{
Shuzhen Guo ${ }^{a}$ Monique Stins ${ }^{c}$ MingMing Ning ${ }^{a, b}$ Eng H. Lo ${ }^{a, b}$ \\ ${ }^{a}$ Neuroprotection Research Laboratory, Departments of Radiology and Neurology, and ${ }^{\mathrm{b}}$ Clinical Proteomics \\ Research Center, Department of Neurology, Massachusetts General Hospital, Harvard Medical School, \\ Boston, Mass., and 'Department of Neurology, Johns Hopkins Medical Center, Baltimore, Md., USA
}

\section{Key Words}

Neurovascular $\cdot$ Inflammation $\cdot$ Blood-brain barrier $\cdot$ Stroke

\begin{abstract}
Background: Increasing evidence suggests that beyond its antiplatelet properties, dipyridamole may have pleiotropic effects on other cells within the neurovascular elements of the brain. In this experimental cellular study, we asked whether dipyridamole can ameliorate brain endothelial injury after exposure to inflammatory and metabolic insults. Methods: Human brain endothelial cells were grown in culture, and exposed to TNF $\alpha$ (continuously for $20 \mathrm{~h}$ ) or subjected to oxygen-glucose deprivation (OGD; $6 \mathrm{~h}$ of insult followed by $18 \mathrm{~h}$ recovery). Expression of ICAM-1, VCAM- 1 and PECAM-1 were measured by immunoblotting. Matrix metalloproteinase-2 (MMP-2) and matrix metalloproteinase-9 (MMP-9) in the conditioned media were quantified via zymography. MTT mitochondrial activity was measured to assess endothelial cell viability. Results: Exposure of human brain endothelial cells to TNF $\alpha(12.5-50 \mathrm{ng} / \mathrm{ml})$ induced a clear increase in protein levels of ICAM-1, VCAM-1 and MMP9. TNF $\alpha$ did not alter PECAM-1. Dipyridamole (1-5 $\mu \mathrm{M})$ significantly attenuated ICAM-1 and MMP-9 levels after this inflammatory insult. No significant effects of dipyridamole were noted for VCAM-1. Six-hour OGD induced moderate
\end{abstract}

endothelial cell death accompanied by a release of MMP-9. Dipyridamole significantly decreased MMP-9 levels and cell death after this metabolic insult. Conclusions: These results suggest that dipyridamole may ameliorate brain endothelial injury after inflammation and/or metabolic insults. How these putative cellular mechanisms may relate to clinical outcomes and conditions in stroke patients remains to be elucidated.

Copyright $\odot 2010$ S. Karger AG, Basel

\section{Introduction}

Dipyridamole, as an antiplatelet agent, is known to inhibit adenosine transporter and phosphodiesterase-5; thus, increasing extracellular levels of adenosine and intracellular levels of cAMP and cGMP. These well-documented actions of dipyridamole provide a major clinical strategy for preventing recurrent vascular events of noncardioembolic etiology in patients with stroke or transient ischemic attack [1-3].

These experiments were funded in part by an academic research grant from Boehringer-Ingelheim to S.G. Boehringer-Ingelheim had no role in study design, data collection, data analysis, data interpretation, writing of the report or the decision to submit for publication.

\section{KARGER}

๑) 2010 S. Karger AG, Basel

Fax +41613061234 E-Mail karger@karger.ch www.karger.com
Shuzhen Guo, PhD

MGH East 149-2401, Charlestown

Boston, MA 02129 (USA)

Tel. +1 617726 4043, Fax +1 6177267830

E-Mailsguo@partners.org 
More recently, however, it has been suggested that dipyridamole may also posses an anti-inflammatory function $[1,3]$. In monocytes incubated with thrombin-stimulated platelets, dipyridamole but not aspirin attenuated the activation of NFкB and blocked the expression of monocyte chemotactic protein-1 and matrix metalloproteinase-9 (MMP-9) [4]. In lipopolysaccharide-challenged macrophages, dipyridamole inhibited p38 MAP kinase, prevented NFKB activation and downregulated cyclooxygenase-2 [5]. In neutrophils, dipyridamole blocked its adhesion to activated endothelial cells, in part by downregulation of macrophage-1 antigen (Mac-1) [6]. In human umbilical vein endothelial cells, dipyridamole attenuated

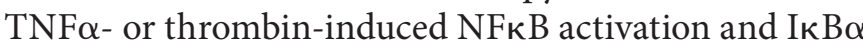
phosphorylation [7]. Taken together, it is conceivable that these pleiotropic effects of dipyridamole may also be relevant in the cerebrovascular system, especially within the context of inflammation during and after stroke.

In the present study, we assessed the effects of dipyridamole using in vitro cultures of human brain endothelial cells subjected to various types of stress. Inflammatory stress was initiated with TNF $\alpha$. Metabolic stress was triggered with oxygen-glucose deprivation (OGD). Our findings showed that dipyridamole partly ameliorated the elevations in adhesion molecules and matrix metalloproteinases triggered by inflammatory stress, and moderately reduced cytotoxicity after metabolic stress.

\section{Materials and Methods}

\section{Cell Culture and Treatment}

A previously characterized human brain microvascular endothelial cell line was used [8]. Cells were seeded in 6 -well plates at $60-70 \%$ confluence and kept at $37^{\circ} \mathrm{C}$ in $5 \% \mathrm{CO}_{2}$. After $6 \mathrm{~h}$ serum starvation, cells were exposed to TNF $\alpha$ (R\&D Systems) with or without dipyridamole (Boehringer Ingelheim) at the same time for $20 \mathrm{~h}$, then cell media were collected for gelatin zymography and cells were used for protein assay or viability assay. Tartaric acid $(2 \mathrm{mM})$ was used as vehicle control for dipyridamole.

To induce OGD, cells were changed to glucose-free DMEM medium, then subjected to hypoxia with a modular chamber (Billups-Rothenberg) and perfused $\left(90 \% \mathrm{~N}_{2}, 5 \% \mathrm{H}_{2}, 5 \% \mathrm{CO}_{2}\right)$ for 30 min $[9,10]$. The chamber was then sealed and incubated at $37^{\circ} \mathrm{C}$. After OGD for $6 \mathrm{~h}$, the cells were returned to a regular incubator with serum-free RPMI-1640 medium for reperfusion over $18 \mathrm{~h}$ with or without dipyridamole. Cell media were collected for gelatin zymography and the cells were used for the viability assay.

\section{Immunoblotting}

Cell lysate was collected with cell lysis buffer (Cell Signaling) after the cells were rinsed twice with ice-cold PBS. Each sample was loaded onto $10 \%$ Tris-glycine gels, $5 \mu \mathrm{g}$ protein for ICAM-1 and $20 \mu \mathrm{g}$ protein for VCAM-1 and PECAM-1. After electropho- resis and transference to PVDF membranes, the membranes were blocked with $5 \%$ non-fat dry milk in Tris-buffered saline for $1 \mathrm{~h}$ at room temperature, then incubated overnight at $4^{\circ} \mathrm{C}$ with primary antibody anti-ICAM-1 (Santa Cruz), antibody anti-VCAM-1 (Chemicon) or antibody anti-PECAM-1 (Abcam). Peroxidaseconjugated secondary antibodies were used for visualization with enhanced chemiluminescence (Pierce). The amount of $\beta$-actin was used as the loading control. The $\mathrm{X}$-ray films were scanned and the optical density of each band was analyzed with Image J. Note that we only focused on cell-membrane-associated adhesion molecules. Hence, our adhesion molecule blots were performed on cell lysates.

\section{MMP Gelatin Zymography}

Conditioned media were collected and centrifuged at $10,000 \mathrm{~g}$ for $2 \mathrm{~min}$ to discard cell debris; the supernatants were concentrated by Vivaspin 500 with a $10-$ KDa cutoff (Sartorius Stedim Biotech). Gelatin zymography was performed as previously described $[10,11]$. Briefly, media samples were mixed with SDS (sodium dodecyl sulfate) sample buffer (Invitrogen) and electrophoresed on $10 \%$ SDS-polyacrylamide gel containing $1 \mathrm{mg} / \mathrm{ml}$ gelatin as the protease substrate (Invitrogen). After electrophoresis, the gels were renatured in Triton X-100 buffer (Novex) for $1 \mathrm{~h}$ and then incubated for $48 \mathrm{~h}$ at $37^{\circ} \mathrm{C}$ in developing buffer (Novex). After developing, the gels were stained with Coomassie Brilliant Blue and photographed. The gelatinase zymogram standards for human MMP-2 and MMP-9 (Chemicon) were loaded as positive controls. MMPs were quantified as fold increase compared with normal controls, as measured by optical density. Note that unlike the cellular responses in adhesion molecules, MMP responses to TNF or OGD are manifested as a release of proteases into extracellular space. Hence, MMP responses are measured in conditioned media.

Cell Viability Assay

Cell viability was determined by standard MTT assay that measures mitochondrial metabolic activity [12]. Endothelial cytotoxicity was calculated as a percentage of untreated controls, i.e. 100 minus percent cell viability. Percent cell death was also confirmed with a standard LDH release assay.

\section{Statistical Analysis}

All of experiments were performed in duplicate or triplicate, and repeated 4-6 times independently. Quantitative data were expressed as mean $\pm \mathrm{SD}$, and analyzed with ANOVA followed by Dunnett's $t$ test. Differences of $\mathrm{p}<0.05$ were considered significant.

\section{Results}

The first set of experiments tested the effects of dipyridamole against an inflammatory stressor. In our brain endothelial cells, the potent cytokine TNF $\alpha(12.5-50 \mathrm{ng} /$ $\mathrm{ml}$ ) clearly increased the protein levels of ICAM-1 and VCAM-1 in a concentration-dependent manner (fig. 1a). There were no detectable responses in PECAM-1 (fig. 
Fig. 1. Dipyridamole reduces $T N F \alpha$-induced adhesion molecule expression in brain endothelial cells. Dip = dipyridamole; con = control; Ve = tartaric acid. $\mathbf{a}$ $\mathrm{TNF} \alpha(12.5 \mathrm{ng} / \mathrm{ml})$ induces an increase in protein levels of adhesion molecules ICAM-1 and VCAM-1 after $20 \mathrm{~h}$ exposure. b Representative blot showing the effects of Dip on TNF $\alpha$-induced expression of ICAM-1. c Optical densitometry quantification for the expression of ICAM-1, normalized to levels of $\beta$-actin $(n=6)$. ${ }^{*} \mathrm{p}<$ 0.05 versus TNF $\alpha$ alone. $\mathbf{d}$ Representative blot showing the effects of Dip on TNF $\alpha$ induced expression of VCAM-1. e Optical densitometry quantification for the expression of VCAM-1, normalized to levels of $\beta$-actin $(n=6)$. a

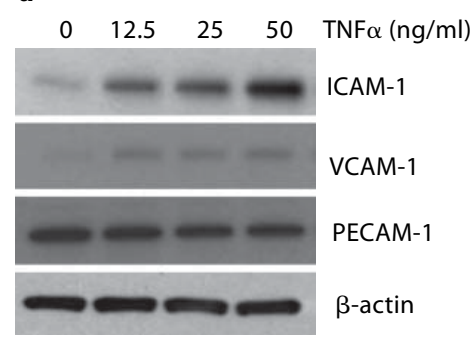

\begin{tabular}{lllll} 
b & \multicolumn{3}{c}{ TNF $\alpha+\operatorname{Dip}(\mu \mathrm{M})$} \\
\cline { 2 - 5 } con & 0 & 1 & 5 & Ve
\end{tabular}

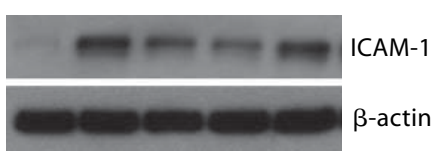

\begin{tabular}{llcrr} 
d & \multicolumn{3}{c}{ TNF $\alpha+\operatorname{Dip}(\mu \mathrm{M})$} \\
\cline { 2 - 5 } con & 0 & 1 & 5 & Ve
\end{tabular}

$-m$ VCAM-1

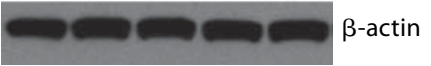

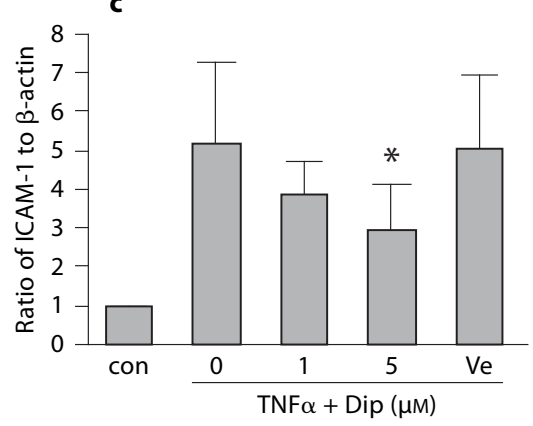

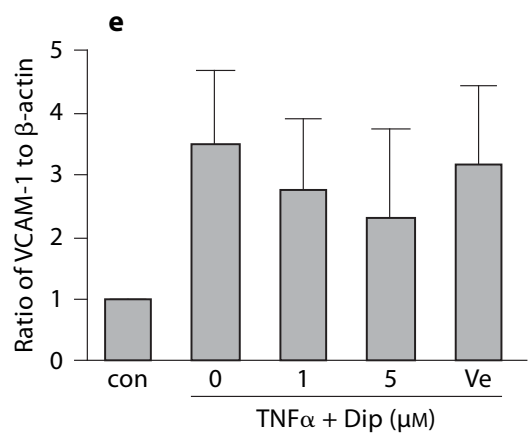

1a). Co-treatment with dipyridamole markedly reduced $\mathrm{TNF} \alpha$-induced ICAM-1 expression; $12.5 \mathrm{ng} / \mathrm{ml} \mathrm{TNF} \alpha$ upregulated ICAM-1 levels by up to 5 -fold and $5 \mu \mathrm{M}$ dipyridamole decreased this response by almost $50 \%$ (fig. 1b, c). Dipyridamole also seemed to slightly affect TNF $\alpha$-induced VCAM-1 responses, but these differences did not reach statistical significance (fig. 1d, e).

TNF $\alpha$ also significantly increased MMP-9 levels in the conditioned media of the brain endothelial cells (fig. 2a). There were no clear effects on MMP-2. At the highest concentration of TNF $\alpha$ tested $(50 \mathrm{ng} / \mathrm{ml})$, secreted MMP-9 levels almost reached 20-fold above baseline (fig. 2b, c). The effects of dipyridamole were tested using a $12.5 \mathrm{ng} / \mathrm{ml}$ concentration of TNF $\alpha$. Co-treatment of dipyridamole $(1-5 \mu \mathrm{M})$ greatly reduced $\mathrm{TNF} \alpha$-induced MMP-9 levels by up to $50 \%$ (fig. 2b, c). Again, there were no statistically significant changes on MMP-2 levels (fig. 2d). In all experiments, there were no detectable effects on endothelial cell viability (fig. 2e), suggesting that no direct cytotoxicity was involved in these MMP responses to $\mathrm{TNF} \alpha$ stimulation.

In the second set of experiments, OGD was used as a trigger of metabolic stress. Brain endothelial cells were subjected to $6 \mathrm{~h}$ OGD followed by $18 \mathrm{~h}$ reperfusion/recov- ery. Injured cells were compared with cells treated with dipyridamole at the onset of reperfusion/recovery. This form of metabolic injury also induced a release of MMP9 into the conditioned media (about 2 -fold, fig. 3a, b). And this response was significantly attenuated by treatment with dipyridamole (fig. 3a, b). No statistically significant changes were noted in MMP-2 (fig. 3c). As expected, this metabolic injury with transient OGD resulted in moderate levels of endothelial cytotoxicity (fig. 3d, e). Treatment with dipyridamole significantly decreased cell death induced by OGD-reperfusion as measured by both MTT (fig. 3d) and $\mathrm{LDH}$ assays (fig. 3e).

\section{Discussion}

Dipyridamole is widely used as an antiplatelet agent in patients at risk of cardiovascular disease and stroke [1-3]. However, emerging data now suggest that dipyridamole may also have important anti-inflammatory actions. In our proof-of-principle study, we showed that dipyridamole significantly ameliorated ICAM-1 and VCAM-1 expression, MMP-9 upregulation and cytotoxicity in brain endothelial cells subjected to inflammatory and metabol- 


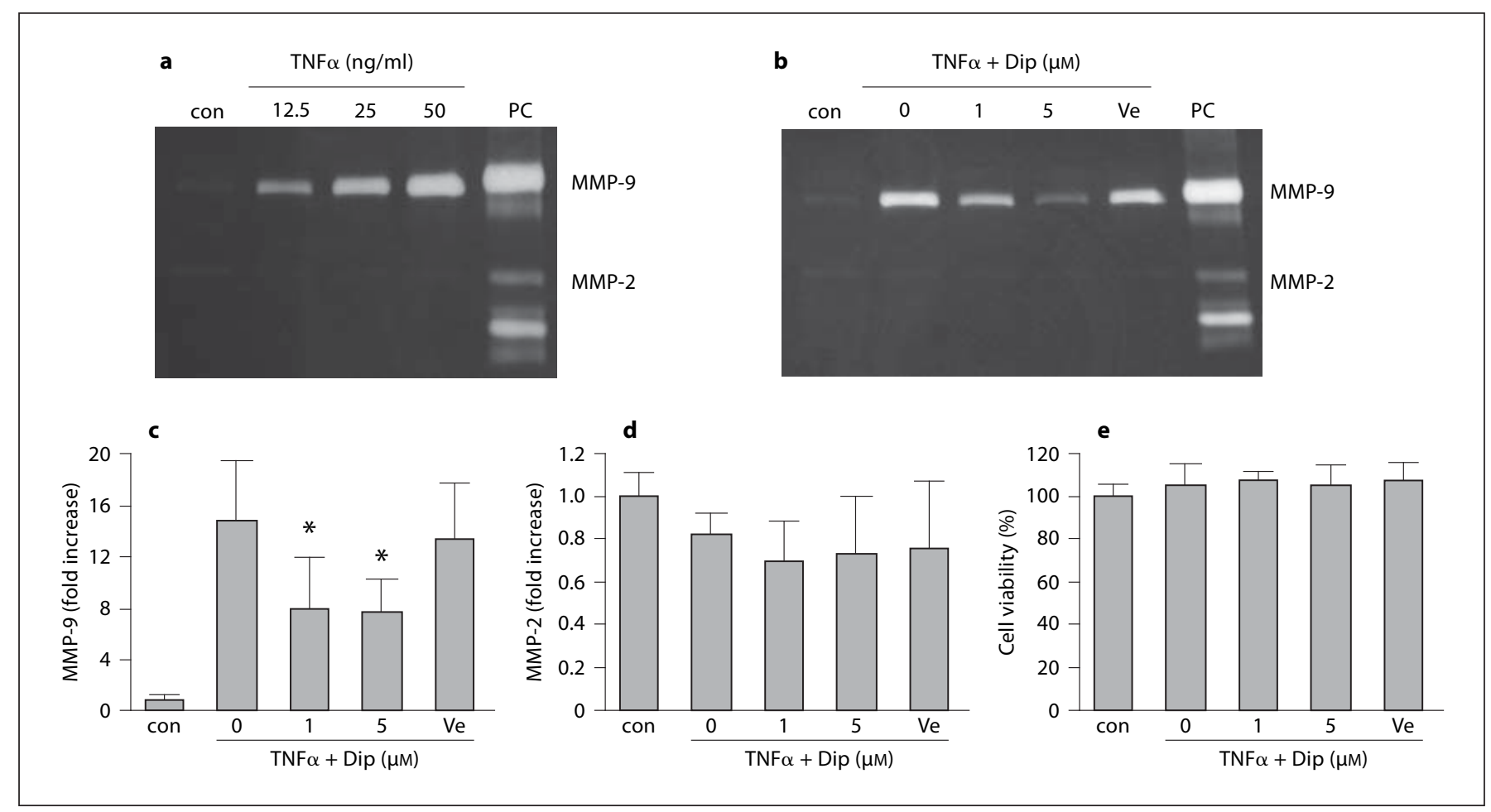

Fig. 2. Dipyridamole reduces TNF $\alpha$-induced MMP-9 in brain endothelial cells. $\mathrm{PC}=$ Positive controls loaded with human MMP-2 and MMP-9 standards; Dip = dipyridamole; Ve = tartaric acid. a Gelatin zymography showing a concentration-dependent response in MMP-9 after TNF $\alpha$. b Representative gel demonstrating the effects of Dip on MMP-9 response after exposure to TNF $\alpha$
(12.5 ng/ml). c Densitometry quantification of MMP-9 in conditioned media. ${ }^{*} \mathrm{p}<0.05$ versus TNF $\alpha$ alone $(\mathrm{n}=6)$. $\mathbf{d}$ Densitometry quantification of MMP-2 in conditioned media. e Under our stimulation conditions, no changes in viability were noted in endothelial cells treated with TNF $\alpha$ and Dip $(n=4)$.

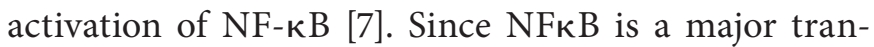
scription factor for adhesion molecules and MMP-9 gene regulation, it is conceivable that this may represent one common mechanism for dipyridamole to reduce ICAM-1, VCAM-1 and MMP-9 expressions in endothelial cells.

In the context of stroke, inflammatory responses in brain endothelial cells are known to contribute to neurovascular pathophysiology [13, 18-22]. ICAM-1 can mediate endothelial activation and transmigration of inflammatory cells [23]. MMP-9 can damage the blood-brain barrier, exacerbate edema and hemorrhage, and worsen neurovascular injury and cell death [14, 24, 25]. Gene knockout or pharmacologic inhibition of ICAM-1 and MMP-9 has been shown to decrease injury in various animal models of stroke [11, 20, 26-30]. In stroke patients, it has been proposed that MMP-9 levels in blood and brain may correlate with clinical outcomes. Hence, the ability of dipyridamole to attenuate inflammatory ICAM- 
a

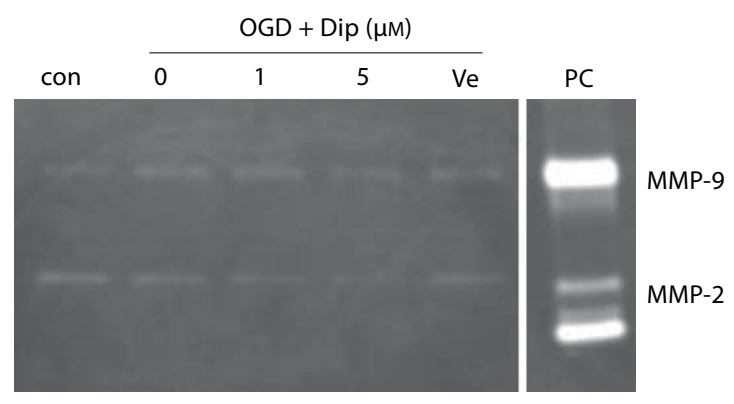

b
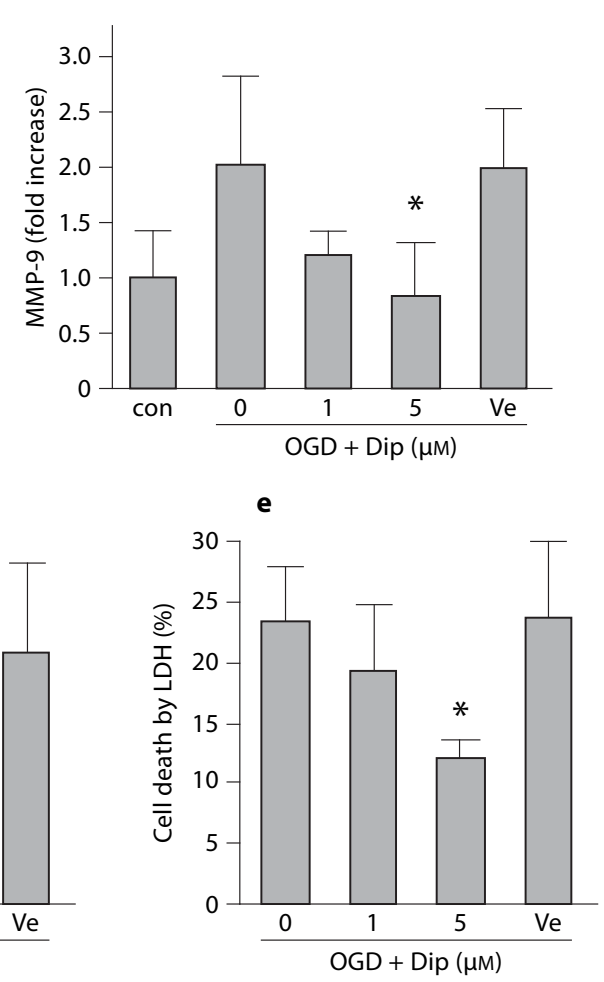

Fig. 3. Dipyridamole (Dip) attenuates OGD-reperfusion-induced MMP-9 and cell death in brain endothelial cells. a Gelatin zymography showing MMP-9 elevation after $6 \mathrm{~h}$ OGD plus $18 \mathrm{~h}$ reperfusion. Treatment with Dip ameliorated these MMP responses. b Densitometry quantification of MMP-9 in conditioned media. ${ }^{*} \mathrm{p}<0.05$ versus OGD-reperfusion alone $(\mathrm{n}=4)$. c Densitometry quantification of MMP-2 in conditioned media. $\mathbf{d}$ Dip reduces endothelial cell death after OGD-reperfusion injury, as measured by MTT assay. ${ }^{*} \mathrm{p}<0.05$ versus OGD-reperfusion alone $(\mathrm{n}=5)$. e Dip reduces endothelial cell death after OGD-reperfusion injury, as measured by LDH release assay. ${ }^{*} \mathrm{p}<0.05$ versus OGDreperfusion alone $(n=4)$.
1 and MMP-9 responses may hint at potential beneficial actions of this drug at the neurovascular level.

Beyond inflammation per se, stroke is obviously a potent metabolic stressor. In cell culture models, this is often mimicked by subjecting cells to OGD. MMP-9 mRNA or activity can be induced by OGD in brain endothelial cells $[31,32]$. In brain endothelial cells, MMP inhibition reduced hypoxic cell death [10]. Here, we found that dipyridamole reduced MMP-9 levels and attenuated cell death in brain endothelial cells. Is it possible that some form of endothelial protection may contribute to potential beneficial properties of dipyridamole in cerebral ischemia? A recent study demonstrated that subtherapeutic doses of dipyridamole combined with simvastatin were able to exert additive NO-dependent vascular effects on a mouse stroke model with increased cerebral blood flow, leading to decreased stroke volume and improved neurologic outcomes [33]. Further investigations appear warranted to truly dissect these neurovascular pathways of dipyridamole in the context of stroke and cerebrovascular disease.

Taken together, our data here provide initial proof-ofprinciple that - independent of its antiplatelet actions dipyridamole can directly ameliorate brain endothelial cell reactions to inflammatory and metabolic stress. However, there are many caveats. First and foremost, our study only provides an initial description of these effects. Further studies are needed to investigate the molecular mechanisms underlying these endothelial responses. Second, our endpoints are limited. Will dipyridamole af- 
fect tight junction proteins or protect the blood-brain barrier? Will dipyridamole attenuate endothelial interactions with inflammatory cells? All these potential effects of dipyridamole warrant further investigation. Thirdly, our findings occur out of context insofar as in vivo brains are concerned. How will dipyridamole affect endothelial function when other cell types are present, including astrocytes, pericytes, neurons etc? The effects of dipyridamole on cell-cell homeostasis in the neurovascular unit will have to be carefully dissected before any of these initial single-cell observations can be properly interpreted.

Finally, a major caveat may arise in terms of how the present data relate to ongoing clinical trials. As early as 1996, the European Stroke Prevention Study 2 (ESPS-2) suggested that aspirin plus extended-release dipyridamole may have benefits over aspirin alone in preventing subsequent stroke [34]. In 2006, the European/Australian Stroke Prevention in Reversible Ischemia Trial (ESPRIT) concluded that combination of dipyridamole with aspirin showed additional risk reduction of stroke and transient ischemic attacks in patients compared with aspirin alone without increased bleeding [35]. Taken together these trials seemed to suggest that dipyridamole might have additional pleiotropic effects on vascular cells beyond antiplatelet actions per se [36]. However, outcomes from the recent PROFESS trial comparing dipyridamole to clopidogrel seemed inconsistent with these earlier trials [37]. How cell biology may be able to help sort out these differences remains to be determined. Correlating in vitro cell culture models with in vivo physiology is extremely difficult. We tried to use concentrations of dipyridamole $(1-5 \mu \mathrm{M})$ that are close to plasma levels in patients, i.e. approximately $4 \mu \mathrm{M}$ in patients taking Aggrenox (aspirin plus extended-release dipyridamole). However, in our experimental paradigms, single shortterm treatments are the norm. How cell signaling responds to short-term versus long-term exposure to dipyridamole is not fully understood.

In conclusion, our cell culture study provided initial proof-of-principle that dipyridamole can directly ameliorate brain endothelial cell responses to inflammatory and metabolic stress. Our findings suggest that beyond its traditional antiplatelet actions, dipyridamole might possess interesting neurovascular effects in brain. Whether and how these cellular observations may relate to stroke and cardiovascular patients remains to be determined.

\section{Acknowledgments}

This study was supported in part by grants from the NIH, a Bugher award from the American Heart Association, and a grant from Boehringer-Ingelheim to S.G.

\section{References}

1 Chakrabarti S, Freedman JE: Dipyridamole, cerebrovascular disease, and the vasculature. Vascul Pharmacol 2008;48:143-149.

2 Bousser MG: Antithrombotic agents in the prevention of ischemic stroke. Cerebrovasc Dis 2009;27(suppl 3):12-19.

-3 Kim HH, Liao JK: Translational therapeutics of dipyridamole. Arterioscler Thromb Vasc Biol 2008;28:s39-s42.

-4 Weyrich AS, Denis MM, Kuhlmann-Eyre JR, Spencer ED, Dixon DA, Marathe GK, et al: Dipyridamole selectively inhibits inflammatory gene expression in platelet-monocyte aggregates. Circulation 2005;111:633642

$\checkmark 5$ Chen TH, Kao YC, Chen BC, Chen CH, Chan P, Lee HM: Dipyridamole activation of mitogen-activated protein kinase phosphatase-1 mediates inhibition of lipopolysaccharide-induced cyclooxygenase-2 expression in RAW 264.7 cells. Eur J Pharmacol 2006;541:138-146.
6 Hallevi H, Hazan-Halevy I, Paran E: Modification of neutrophil adhesion to human endothelial cell line in acute ischemic stroke by dipyridamole and candesartan. Eur J Neurol 2007;14:1002-1007.

7 Chakrabarti S, Blair P, Wu C, Freedman JE: Redox state of dipyridamole is a critical determinant for its beneficial antioxidant and antiinflammatory effects. J Cardiovasc Pharmacol 2007;50:449-457.

-8 Callahan MK, Williams KA, Kivisakk P, Pearce D, Stins MF, Ransohoff RM: CXCR3 marks CD4+ memory $\mathrm{T}$ lymphocytes that are competent to migrate across a human brain microvascular endothelial cell layer. J Neuroimmunol 2004;153:150-157.

-9 Arai K, Lo EH: An oligovascular niche: cerebral endothelial cells promote the survival and proliferation of oligodendrocyte precursor cells. J Neurosci 2009;29:4351-4355.

10 Lee SR, Lo EH: Induction of caspase-mediated cell death by matrix metalloproteinases in cerebral endothelial cells after hypoxia-reoxygenation. J Cereb Blood Flow Metab 2004;24:720-727.
Amelioration of Inflammation and Cytotoxicity by Dipyridamole 
-15 Franzen B, Duvefelt K, Jonsson C, Engelhardt B, Ottervald J, Wickman M, et al: Gene and protein expression profiling of human cerebral endothelial cells activated with tumor necrosis factor-alpha. Brain Res Mol Brain Res 2003;115:130-146.

16 Hanemaaijer R, Koolwijk P, le Clercq L, de Vree WJ, van Hinsbergh VW: Regulation of matrix metalloproteinase expression in human vein and microvascular endothelial cells: effects of tumour necrosis factor alpha, interleukin 1 and phorbol ester. Biochem J 1993;296(part 3):803-809.

-17 Siminiak T, Smielecki J, Rzezniczak J, Kazmierczak M, Kalawski R, Wysocki H: The effects of dipyridamole stress test on plasma levels of soluble adhesion molecules intracellular adhesion molecule-1, vascular cell adhesion molecule-1, E-selectin and L-selectin in patients with ischemic heart disease and patients with syndrome X. Coron Artery Dis 1999; 10:235-240.

-18 Nelimarkka LO, Nikkari ST, Ravanti LS, Kahari VM, Jarvelainen HT: Collagenase-1, stromelysin-1 and $92 \mathrm{kDa}$ gelatinase are associated with tumor necrosis factor-alpha induced morphological change of human endothelial cells in vitro. Matrix Biol 1998; 17:293-304

-19 Zeni P, Doepker E, Schulze-Topphoff U, Huewel S, Tenenbaum T, Galla HJ: MMPs contribute to TNF-alpha-induced alteration of the blood-cerebrospinal fluid barrier in vitro. Am J Physiol Cell Physiol 2007; 293:C855-C864.

-20 Amantea D, Nappi G, Bernardi G, Bagetta G, Corasaniti MT: Post-ischemic brain damage: pathophysiology and role of inflammatory mediators. FEBS J 2009;276:13-26.

21 del Zoppo GJ: Inflammation and the neurovascular unit in the setting of focal cerebral ischemia. Neuroscience 2009;158:972-982.
22 Frijns CJ, Kappelle LJ: Inflammatory cell adhesion molecules in ischemic cerebrovascular disease. Stroke 2002;33:2115-2122.

-23 Stanimirovic D, Shapiro A, Wong J, Hutchison J, Durkin J: The induction of ICAM-1 in human cerebromicrovascular endothelial cells (HCEC) by ischemia-like conditions promotes enhanced neutrophil/HCEC adhesion. J Neuroimmunol 1997;76:193-205.

24 Rosell A, Lo EH: Multiphasic roles for matrix metalloproteinases after stroke. Curr Opin Pharmacol 2008;8:82-89.

25 Zhao BQ, Tejima E, Lo EH: Neurovascular proteases in brain injury, hemorrhage and remodeling after stroke. Stroke 2007;38:748752.

26 Svedin P, Hagberg H, Savman K, Zhu C, Mallard C: Matrix metalloproteinase-9 gene knock-out protects the immature brain after cerebral hypoxia-ischemia. J Neurosci 2007; 27:1511-1518.

27 Connolly ES Jr, Winfree CJ, Springer TA, Naka Y, Liao H, Yan SD, et al: Cerebral protection in homozygous null ICAM-1 mice after middle cerebral artery occlusion: role of neutrophil adhesion in the pathogenesis of stroke. J Clin Invest 1996;97:209-216.

28 Soriano SG, Lipton SA, Wang YF, Xiao M, Springer TA, Gutierrez-Ramos JC, et al: Intercellular adhesion molecule-1-deficient mice are less susceptible to cerebral ischemia-reperfusion injury. Ann Neurol 1996; 39:618-624.

29 Zhang RL, Chopp M, Li Y, Zaloga C, Jiang N, Jones ML, et al: Anti-ICAM-1 antibody reduces ischemic cell damage after transient middle cerebral artery occlusion in the rat. Neurology 1994;44:1747-1751.

30 Asahi M, Wang X, Mori T, Sumii T, Jung JC, Moskowitz MA, et al: Effects of matrix metalloproteinase-9 gene knock-out on the proteolysis of blood-brain barrier and white matter components after cerebral ischemia. J Neurosci 2001;21:7724-7732.
31 Leonardo CC, Hall AA, Collier LA, Gottschall PE, Pennypacker KR: Inhibition of gelatinase activity reduces neural injury in an ex vivo model of hypoxia-ischemia. Neuroscience 2009;160:755-766.

-32 Yang MZ, Mun CH, Choi YJ, Baik JH, Park KA, Lee WT, et al: Agmatine inhibits matrix metalloproteinase-9 via endothelial nitric oxide synthase in cerebral endothelial cells. Neurol Res 2007;29:749-754.

>33 Kim HH, Sawada N, Soydan G, Lee HS, Zhou Z, Hwang SK, et al: Additive effects of statin and dipyridamole on cerebral blood flow and stroke protection. J Cereb Blood Flow Metab 2008;28:1285-1293.

>34 Diener HC, Cunha L, Forbes C, Sivenius J, Smets P, Lowenthal A: European Stroke Prevention Study. 2. Dipyridamole and acetylsalicylic acid in the secondary prevention of stroke. J Neurol Sci 1996;143:1-13.

-35 Halkes PH, van Gijn J, Kappelle LJ, Koudstaal PJ, Algra A: Aspirin plus dipyridamole versus aspirin alone after cerebral ischaemia of arterial origin (ESPRIT): randomised controlled trial. Lancet 2006;367:1665-1673.

36 Verro P, Gorelick PB, Nguyen D: Aspirin plus dipyridamole versus aspirin for prevention of vascular events after stroke or TIA: a meta-analysis. Stroke 2008;39:1358-1363.

$\checkmark 37$ Diener HC, Sacco RL, Yusuf S, Cotton D, Ounpuu S, Lawton WA, et al: Effects of aspirin plus extended-release dipyridamole versus clopidogrel and telmisartan on disability and cognitive function after recurrent stroke in patients with ischaemic stroke in the Prevention Regimen for Effectively Avoiding Second Strokes (PRoFESS) trial: a doubleblind, active and placebo-controlled study. Lancet Neurol 2008;7:875-884. 